\title{
Application of Flipped Classroom Teaching Model in Intercultural Communication Courses in Universities and Colleges in Yunnan Province
}

\author{
Ping Yang \\ School of Foreign Language \\ Kunming University \\ Kunming, Yunnan, 650214
}

\author{
Shi Qian \\ School of Fine Art and Design \\ Kunming University \\ Kunming, Yunnan, 650214
}

\begin{abstract}
The "bridgehead" strategy and "the Belt and Road Initiative" strategy have transformed Yunnan from a southwestern border area into the front and core of opening the southwestern region to the world. In terms of the reality of social development and education in Yunnan, under the new background of the times, Yunnan is in urgent need of cultivating fore ign language talents who can meet the needs of economic and social development. In the current foreign language teaching in colleges and universities in Yunnan, due to a series of reasons such as insufficient interaction time in classes, students' lack of spontaneous learning abilities and insufficient degree of internalization of knowledge and others, there are pervasive problems of over-strengthening the learning of cultural knowledge and weakening the cultivation of the abilities for language outputs and communicative practices. Flipped classroom teaching model uses modern information technology to acquire the cultural knowledge before class and its advantages of using teaching time for experiment, in-class discussion, project training and team cooperation can be used to make up for the weaknesses and deficiencies of traditional foreign language teaching in colleges and universities in Yunnan. This paper attempts to integrate the teaching model of flipped class room into the teaching of cross-cultural communication courses in colleges and universities in Yunnan to improve students ' abilities in crosscultural thinking and communications, and provides some experience and reference for the application and localization of this new teaching model in the cross-cultural communication courses in Yunnan Province.
\end{abstract}

Keywords-Flipped classroom teaching model; Cross-cultural communication courses

Risen in the international educational community in 2011, flipped classroom which is based on theory of constructivism, is against the traditional teaching model of "classroom teaching and after-school assignments” in China. Because this teaching method is feasible, facilitates the transmission and absorption of knowledge and its effects are evident, it has caught people' eyes since its appearance at home and abroad.

As an educational model supported by information technology, the teaching model of the flipped classroom promotes the combination of education and technology and the innovation of education. The Ten-Year Development Plan for the Application of Information Technology in Education (20112020) of China points out that 'the development of the application of information technology in education should take the innovation of educational ideas as the guide, the establishment of educational resources and information technology learning environment as the basics and the innovations on learning and educational modes as the core".[1] The flipped classroom teaching model conforms to the general trend of the application of information technology in education. With its continuous development, its practical application effects have gained more and more recognition and it has become a hot topic of the innovation and an important direction in the reform of current higher education in China.

\section{The History of FlipPed Classroom Teaching MODEL}

At the end of the 20th century, with the rapid development of science and technology the richness and extensiveness of educational practice promote the improvement of teaching methods. Educational researchers in the United States have begun to focus on learners' psychological development and role orientation. Professor Eric Mazur of Harvard University, Salman Khan of Khan College, and two chemistry teachers, Jonathan Bergman and Aaron Sams at Woodland Park High School in the United States, have all made tremendous efforts to the exploration and development of flipped classroom teaching model. This teaching model has attracted the attention of many educators, and more and more them have applied it to their teaching practice.

In recent years, the flipped classroom teaching model has attracted more and more educators' attention in China. But on the whole, domestic research is still in the initial stage of learning from overseas. The research mainly focuses on the introduction and enlightenment of relevant research in the United States, the exploration and design of teaching model, the bottleneck and direction of development, and the challenges. Generally, in terms of the regions where the researchers and research on flipped classroom are located, the current research of it mainly focuses on the economically developed areas, such as Jiangsu, Guangdong and Shanghai, followed by Jiangxi, Henan, Hebei and few in the western areas. As for the contents of the study, most of them are theoretical research, which is lack of fact-finding, comprehensive and systematic investigations and studies.[2] The absence of these studies has affected its practical effect. For the perspective of research, most of it tends to be 
macroscopic and there is not much study of the practical problems. Overall, empirical studies are few and far from enough. Previous studies on flipped classroom focus more on primary and secondary schools than on universities and more on information technology courses rather than on foreign language courses.

At present, flipped classroom teaching model is accepted by more and more colleges and universities in Europe and America, and has gradually developed into a new wave of educational reform. The study of it has also arisen in various fields of developed areas in China, but its application and research is only in a blank state in the field of college English teaching and educators almost can not find a relevant works.

\section{Connotation of the New Teaching Model of FlipPed ClassRoOM IN THE CROSS-CULTURAL COMMUNICATION COURSES IN COLLEGES AND UNIVERSITIES IN YUNNAN PROVINCE.}

\section{A. Status of the Teaching for Intercultural Communicative Abilities}

With increasing international communications and exchanges, the world has an increasing demand for crosscultural communication talents. Cross-cultural communications have become one of the important goals of talent training in the 21st century. College English Teaching Guide issued by the Ministry of Education in 2015 clearly points out that college students should "understand the society and culture of foreign countries, enhance their understanding of different cultures and their awareness of the similarities and differences between Chinese and foreign cultures, and cultivate their intercultural communicative abilities" [3]. According to surveys, the crosscultural communicative abilities of non-English majors in China is not optimistic, with a relatively low overall level of intercultural communications.[4] How to cultivate and improve the cross-cultural communicative abilities of college students has become an important topic in cross-cultural researches. In particular, within an effective teaching time limit, how to help college students acquire knowledge of cross-cultural communication and apply it to practices so as to enhance their skills and awareness of cross-cultural communication and stimulate the students' abilities to take the initiative to explore and construct a knowledge system, has become a problem to be solved in the cross-cultural communication teaching. Obviously, it is difficult to achieve the goal of cultivating college students' cross-cultural communicative abilities in the traditional classrooms focusing on imparting knowledge. [5]

\section{B. Connotations of the New Teaching Model of Flipped Classroom in the Cross-cultural Communication Courses in Colleges and Universities in Yunnan Province}

In terms of the reality of social development and education in Yunnan, under the background of the Bridgehead Strategy and the Belt and Road Initiative, Yunnan is in urgent need of high-quality cross-cultural communication talents who can adapt to the requirements of social and economic development. As mentioned above, Yunnan is located on the border, with relatively backward education. Yunnan colleges and universities face such constraints and problems like obviously lagging cultivation in foreign language talents, insufficient interactive times in the classes, students' lack of spontaneous learning abilities and insufficient internalization of knowledge. On the other side, few educators try to explore this new teaching model and its absorption lags far behind in the educational domain in Yunnan Province, which undoubtedly severely restricts the improvement of the qualities of foreign language talents training in Yunnan universities.

Undoubtedly, promoting the exploration and study of this new teaching theory and model proved effective in practice at home and abroad and its application and promotion in the English teaching, with considerations on Yunnan's own unique educational historical and cultural background and practices, is helpful to promote the reform of traditional teaching methods in Yunnan colleges and universities which rely heavily on classroom teaching links, greatly improve the efficiency of foreign language teaching and training of quality talents in colleges and universities. It has broad practical application prospects, research values and expansion potentials.

\section{A Probe INTO the Teaching Model of FliPPED ClassroOM IN THE CROSS-CULTURA COMMUNICATION COURSES IN COLLEGES AND UNIVERSITIES IN YUNNAN PROVINCE}

One of the characteristics of the teaching model of flipped classroom is to complete the study of knowledge by means of multimedia and other modern educational techniques before class, so that in the classes the teacher and the students can interact and communicate to finish the assignments and internalize and deepen the knowledge. The teaching process with pre-class learning and in-class exercises is completely different from the traditional teaching model of in-class learning and after-class practices in Yunnan colleges and universities. This paper, takes the task-based and case-based teaching methods (often used in flipped classroom) and the comparison and contrast of the Chinese and Western concepts on love as the teaching content, has designed two 45-minute sessions following the flipped classroom. The specific steps are as follows: Guides the students to learn and understand the Chinese and Western concepts of love (knowledge input). Then analyzes the similarities and differences between Chinese and Western concepts of love (the establishment of cross-cultural communication consciousness) from the perspective of social, historical and cultural backgrounds and explores how to establish a correct concept of love (the cultivation of crosscultural communication skills).[6]

The first step is pre-class learning with the help of the teacher. The main purposes of pre-class learning are to promote and help students complete the cross-cultural knowledge input and absorption. The teacher can provide materials such as videos and courseware such as Liang Zhu and Jane Eyre, which are representative classic love literature works of Chinese and Western countries and send them to the class QQ group. About five students form a group. Through watching the materials distributed by the teacher, they understand some of the traditional concepts of love in China and the West and discuss the similarities and differences between Chinese and Western concepts of love in the group. In this process, the teacher can also put forward some related questions on the 
students' pre-class learning so that students can discuss or answer written questions. In this way, the teacher can judge the students' understanding of the curriculum content and arrange the following teaching according to the students' learning.

The second step is to internalize the knowledge under the guidance of the teacher in the classroom. Under the concepts of flipped classroom, the in-class Q\&A, discussions and communication constitute a vital stage of checking, consolidating and improving students' understanding and absorption of knowledge, with a purpose to help students absorb and internalize knowledge further. In class, under the guidance of the teacher, students discuss and explore on the existing problems in the first stage of the study process, focusing on solving the problems arising from the discussions and answering written questions after they watch videos. In addition, after answering pre-class questions, under the guidance of the teacher, teaching activities through group interactions and cooperation are carried out to improve the students' abilities to apply and expand what they have learned. The teacher can use typical cases (such as Liang Shanpo and Zhu Yingtai and Jane Eyre and others) to guide and organize students to discuss and requires them to compare and analyze the following questions. 1 . The attitudes of China and the West towards love. 2. Chinese and Western ways of expressing love. 3. The connotations of love in China and the West. 4. The relationship between love and marriage in China and the West. In view of the above problems, the teacher guides the students to discuss the cases, and requires them to summarize on the following issues. 1. Western concepts of love; 2 . The Oriental concepts of love. 3. How to cultivate a correct concept of love. After analyzing the cases, the teacher guides students again to analyze the differences between Chinese and Western cultures from the perspective of social, historical and cultural backgrounds, and guides them to raise their awareness of the concepts of love in China and the West.[7] Finally, the teacher guides students to discuss how to establish a correct concept of love to enhance students' cross-cultural skills. Through the case study and discussion, the pre-class cross-cultural knowledge learned by students is internalized in the classroom. In the teaching model of flipped classroom, students deepen their understanding and absorption of cross-cultural knowledge, and enhance their cross-cultural skills and awareness.

The third step is timely after-class feedback. An important feature of flipped classroom is the immediacy of the feedbacks on teaching. Based on the students' pre-class learning of Chinese and Western concepts of love, the main problems and doubts that students have, the students' in-class activeness in discussing Chinese and Western concepts on love, the degree of the internalization of the relevant cross-cultural knowledge and the improvement of the cross-cultural skills, teachers can reflect on the effectiveness of their own teaching objectives and the appropriateness of teaching ways and methods, so as to further reflect on the shortcomings and advantages of teaching in the future and improve the effectiveness in the future crosscultural communication teaching. Besides, the teacher should also know the students' learning progress and effects, give timely feedbacks on students' doubts and requirements, and give targeted guidance to their existing problems.

Through the pre-class input of cross-cultural communication knowledge, the in-class internalization of cross-cultural knowledge, cultivation of the cross-cultural skills and raise of the cross-cultural awareness and the after-class reflections and improvement, flipped classroom is not only conducive to imparting cross-cultural knowledge to students but also to cultivating students' cross-cultural sensitivity and awareness and improving their cross-cultural communicative abilities, [8] so as to achieve the goal of appropriate and effective cross-cultural communication.

\section{CONCLUSION}

The flipped classroom teaching model integrates modern scientific and technological means with education, and promotes the innovation and perfection of teaching methods. Flipped classroom uses modern information technology to acquire the cultural knowledge before class. The advantages of using teaching time for experiment, in-class discussion, project training and team cooperation can be used to make up for the weaknesses and deficiencies of traditional foreign language teaching in Yunnan colleges and universities. This paper believes that the effective reform and innovation and more practice and empirical researches on flipped classroom teaching model will enrich the theoretical system and academic connotations. It is of great significance to improve the teaching efficiency of teachers, the learning performance of students and the improvement of education.

\section{ACKNOWLEDGEMENT}

This article is the periodical achievement of the project funded by provincial department of education in Yunnan (project number: 2017ZDX050)

\section{REFERENCES}

[1] Zhang Jinlei. The Analysis of the Key Factors of Flipped Classroom Teaching Mode [J]. Distance Education in China, 2013(10)59-64.

[2] Fu Xiaoxia. A Study on the Effect of Flipping Classroom on College English Grammar Teaching[J]. Hunan Normal University, 2016.

[3] Ren Xiu, Duan Huiru, Deng Jun. The New Teaching Mode of Flipped Classroom in Cross Cultural Communication [J]. Entrepreneurship and Entrepreneurship Education, 2016(7) 97-100.

[4] Wang Xiaohui. The Application of Intercultural Communication Teaching in Cultivating Intercultural Communicative Competence of Non English Majors [J]. Bohai University, 2013.

[5] Ren Xiu, Duan Huiru, Deng Jun. The New Teaching Mode of Flipped Classroom in Cross Cultural Communication [J]. Entrepreneurship and Entrepreneurship Education, 2016(7) 97-100.

[6] Ibid.

[7] Yu She. An Investigation into Intercultural Communicative Competence in College English Learning[J]. Jiangxi Normal University, 2016.

[8] Zhang Ruisi. Analysis of Flipped Classroom Model in Intercultural Communication Curriculum[J]. Overseas English, 2016. 